\title{
First report of a mucosa-associated lymphoid tissue (MALT) lymphoma of the esophagus diagnosed by endoscopic ultrasound-guided fine-needle aspiration (EUS-FNA)
}

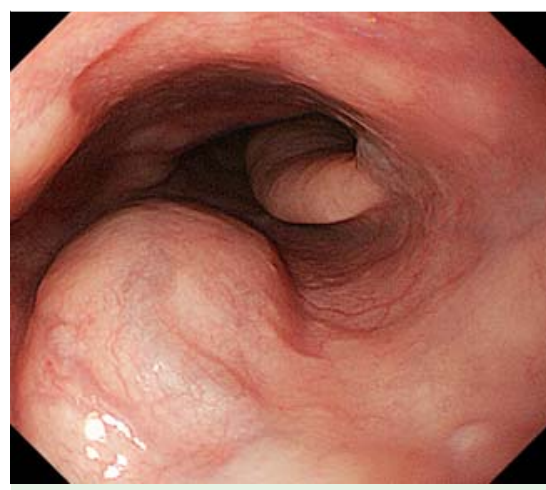

Fig. 1 Endoscopic findings in a 60-year-old woman with dysphagia: a large, rounded mass with normal overlying mucosa is seen extending longitudinally along the entire esophagus.

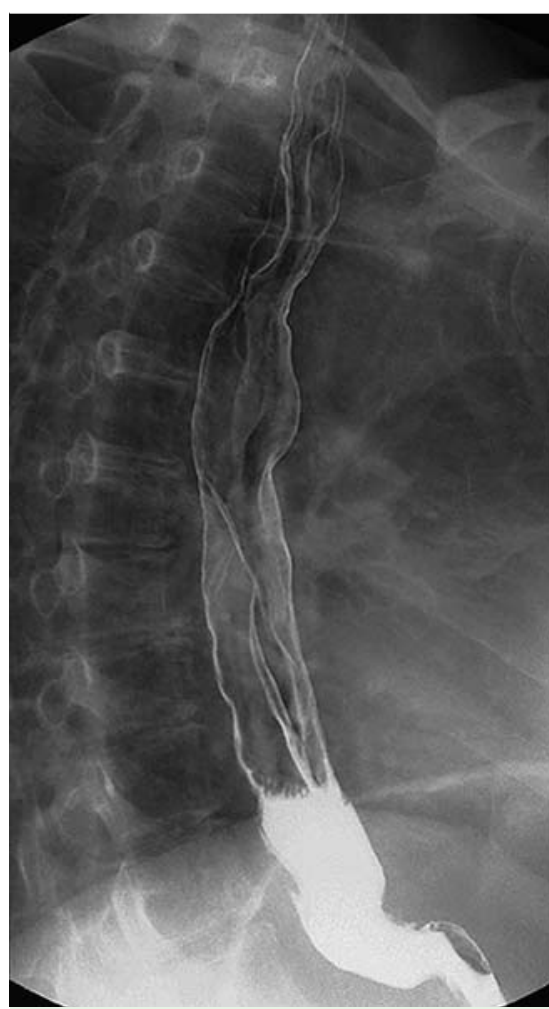

Fig. 2 Esophagogram showing a large submucosal tumor with luminal narrowing of the whole of the esophagus.

Mucosa-associated lymphoid tissue (MALT) lymphoma of the esophagus is a rare tumor [1-3] with varying presentations [4]. Only a few reports have de-

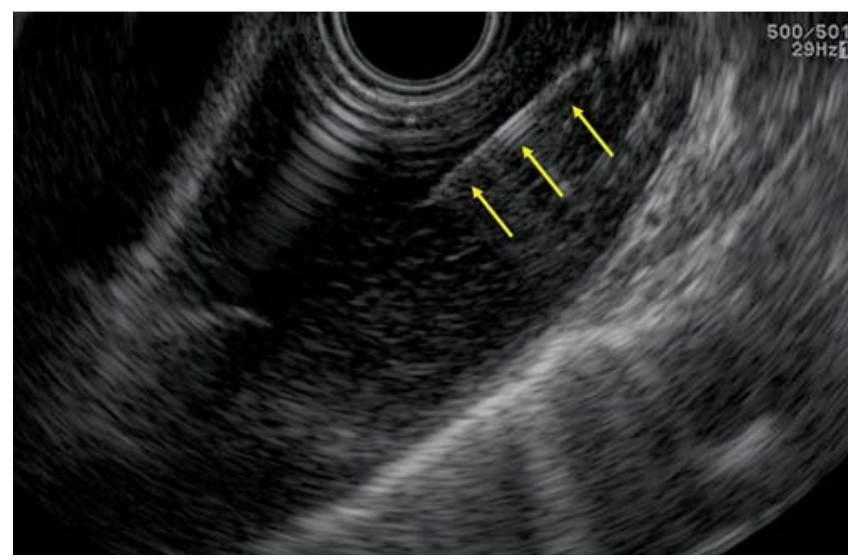

Fig. 3 Endoscopic ultrasound showing a hypoechoic thickening in the third layer. Endoscopic ultrasoundguided fine-needle aspiration was carried out using a 22-G needle (arrows).

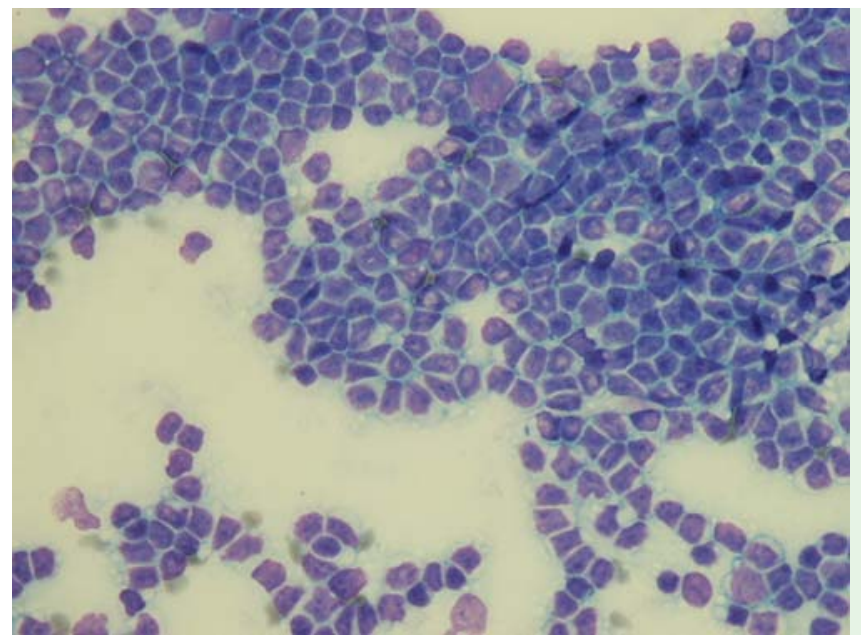

Fig. 4 Small- to medium-sized lymphocytic cells with mildly irregular nuclei.

scribed MALT lymphoma of the esophagus spanning the entire circumference and length of the esophagus [3]. Many of these cases were diagnosed surgically. Endoscopic ultrasound-guided fine-needle aspiration (EUS-FNA) is an established method of obtaining submucosal tissue specimens [5]. We report here the first case of MALT lymphoma of the esophagus diagnosed by EUS-FNA.

A 60-year-old woman attended our institution due to dysphagia. Upper gastrointestinal endoscopy revealed a smooth surface with visible capillaries over the entire circumference of the esophagus and a white, soft, elastic submucosal tumor covered by normal mucosa ( $\bullet$ Fig. 1). An esophagogram showed a slightly elevated submucosal tumor extending over the entire esophageal length ( $\bullet$ Fig.2), and enhanced computed tomography demonstrated thickening of the left bronchial and esophageal walls along with swelling of the pharyngeal lymph nodes. Endoscopic ultrasonography revealed a tumorous lesion presenting as a primarily hypoechoic mass arising in the third layer, with a hyperechoic region.

Because a diagnosis was not reached using specimens obtained with biopsy forceps, EUS-FNA was performed ( Fig.3). The presence of small- to medium-sized lymphocytic cells with mildly irregular nuclei, along with $\mathrm{CD} 5(-), \mathrm{CD} 10(-), \mathrm{CD} 19(+)$, CD20(+), CD22 (+), and $\lambda$ monoclonality on flow cytometry, led to a diagnosis of MALT lymphoma of the esophagus (ه Fig.4). We described the tumor as a 
malignant, extramarginal zone B-cell lymphoma of the MALT type, clinical stage IV (Lugano International Conference classification). The patient was treated with a total of six courses of chemotherapy with rituximab, cyclophosphamide, vincristine, doxorubicin, and prednisolone (R-CHOP), and a complete response was achieved.

To the best of our knowledge, this is the first report of EUS-FNA diagnosis of MALT lymphoma of the esophagus.

Endoscopy_UCTN_Code_CCL_1AB_2AC_3AB

Competing interests: None
T. Ogura ${ }^{1,2}$, M. Tajika ${ }^{3}$, S. Hijioka ${ }^{1}$,

K. Hara ${ }^{1}$, S. Haba ${ }^{1}$, W. Hosoda ${ }^{4}$,

Y. Yatabe ${ }^{4}$, S. Asano ${ }^{5}$, K. Higuchi², K. Yamao ${ }^{1}$, Y. Niwa ${ }^{3}$

${ }^{1}$ Department of Gastroenterology, Aichi Cancer Center Hospital, Nagoya, Japan

2 2nd Department of Internal Medicine, Osaka Medical College, Osaka, Japan

${ }^{3}$ Department of Endoscopy, Aichi Cancer Center Hospital, Nagoya, Japan

${ }^{4}$ Department of Pathology and Molecular Diagnostics, Aichi Cancer Center Hospital, Nagoya, Japan

${ }^{5}$ Department of Respiratory Medicine, Handa Municipal Hospital, Nagoya, Japan

\section{References}

1 Lewin KL, Ranchod M, Dorfman RF et al. Lymphomas of the gastrointestinal tract: a study of 117 cases presenting with gastrointestinal disease. Cancer 1978; 42: 693-707

2 Brady LW, Asbell SO. Malignant lymphoma of the gastrointestinal tract. Erskine Memorial Lecture, 1979. Radiology 1980; 137: 291 298

3 Kishi K, Maedu H, Nakamura Y et al. Radiotherapy for mucosa-associated lymphoid tissue (MALT) lymphoma of the esophagus: a case report with a diagnostic and therapeutic discussion. Int J Clin Oncol 2011: Jun 10 (Epub ahead of print)

4 Carnovale RL, Goldstein HM, Zornoza J et al. Radiologic manifestations of esophageal lymphoma. AJR Am J Roentgenol 1977; 128: $751-754$

5 Yamao K, Sawaki A, Mizuno $N$ et al. Endoscopic ultrasound-guided fine-needle aspiration biopsy (EUS-FNAB): Past, present, and future. J Gastroenterol 2005; 40: 1013-1023

\section{Bibliography}

DOI http://dx.doi.org/

10.1055/s-0031-1291758

Endoscopy 2012; 44: E167-E168

(c) Georg Thieme Verlag KG

Stuttgart · New York

ISSN 0013-726X

\section{Corresponding author}

\section{Tajika}

1-1 Kanokoden

Chikusa-ku

Nagoya 464-8681

Japan

Fax: +81-527635233

mtajika@aichi-cc.jp 